\title{
Practical one-dimensional measurements of (cossuate age-related brain atrophy are validated by 3-dimensional values and clinical outcomes: a retrospective study
}

\author{
C. Michael Dunham ${ }^{1 *}$, Albert J. Cook $\|^{2}$, Alaina M. Paparodis ${ }^{2}$ and Gregory S. Huang ${ }^{1}$
}

\begin{abstract}
Background: Age-related brain atrophy has been represented by simple 1-dimensional (1-D) measurements on computed tomography (CT) for several decades and, more recently, with 3-dimensional (3-D) analysis, using brain volume (BV) and cerebrospinal fluid volume (CSFV). We aimed to show that simple 1-D measurements would be associated with 3-D values of age-related atrophy and that they would be related to post-traumatic intracranial hemorrhage $(\mathrm{ICH})$.
\end{abstract}

Methods: Patients $\geq 60$ years with head trauma were classified with central atrophy (lateral ventricular body width $>30 \mathrm{~mm}$ ) and/or cortical atrophy (sulcus width $\geq 2.5 \mathrm{~mm}$ ). Composite atrophy was the presence of central or cortical atrophy. BV and CSFV were computed using a Siemens Syngo workstation (VE60A).

Results: Of 177 patients, traits were age $78.3 \pm 10, \mathrm{ICH} 32.2 \%$, central atrophy $39.5 \%$, cortical atrophy $31.1 \%$, composite atrophy $49.2 \%$, BV 1,156 $\pm 198 \mathrm{~mL}$, and CSFV $102.5 \pm 63 \mathrm{~mL}$. CSFV was greater with central atrophy $(134.4 \mathrm{~mL})$, than without $(81.7 \mathrm{~mL}, p<0.001)$. BV was lower with cortical atrophy $(1,034 \mathrm{~mL})$, than without $(1,211 \mathrm{~mL} ; p<0.001)$. BV was lower with composite atrophy $(1,103 \mathrm{~mL})$, than without $(1,208 \mathrm{~mL} ; p<0.001)$. CSFV was greater with composite atrophy $(129.1 \mathrm{~mL})$, than without $(76.8 \mathrm{~mL}, p<0.001)$. CSFV $\div$ BV was greater with composite atrophy $(12.3 \%)$, than without $(6.7 \%, p<0.001)$. Age was greater with composite atrophy (80.4 years), than without $(76.3, p=0.006)$. Age had an inverse correlation with BV $(p<0.001)$ and a direct correlation with CSFV $(p=0.0002)$ and CSFV $\div$ BV $(p<0.001)$. ICH was greater with composite atrophy (49.4 \%), than without $(15.6 \% ; p<0.001$; odds ratio $=5.3)$. BV was lower with $\mathrm{ICH}(1,089 \mathrm{~mL})$, than without $(1,188 \mathrm{~mL}$; $p=0.002)$. CSFV $\div$ BV was greater with $\mathrm{ICH}(11.1 \%)$, than without $(8.7 \%, p=0.02)$. ICH was independently associated with central atrophy $(p=0.001)$ and cortical atrophy $(p=0.003)$.

Conclusions: Simple 1-D measurements of age-related brain atrophy are associated with 3-D values. Clinical validity of these methods is also supported by their association with post-injury ICH. Intracranial 3-D software is not available on many CT scanners and can be cumbersome, when available. Simple 1-D measurements, using the study methodology, are a practical method to objectify the presence of age-related brain atrophy.

Keywords: Brain atrophy, Traumatic intracranial hemorrhage, CT imaging

\footnotetext{
* Correspondence: dunham.michael@sbcglobal.net

${ }^{1}$ Trauma/Critical Care Services, St. Elizabeth Youngstown Hospital, 1044

Belmont Avenue, Youngstown, OH 44501, USA

Full list of author information is available at the end of the article
} 


\section{Background}

Although brain atrophy has been touted for several decades as a risk for post-traumatic intracranial hemorrhage $(\mathrm{ICH})$, our group recently provided the only published evidence validating this notion [1]. Specifically, we showed that 1-dimensional (1-D) estimates of atrophy on brain computed tomography (CT) have an association with the rate of $\mathrm{ICH}$. For several decades, investigators have used 1-D measurements to indicate the presence of age-associated brain atrophy. The primary representations of brain atrophy have been lateral ventricular enlargement [2-5] and cortical sulcal widening $[2,3,6-12]$. At least six investigations of non-demented patients have indicated that with advancing age, the ventricular or intracranial cerebrospinal fluid (CSF) volume increases [13-17] and the brain volume decreases [13-15, 17, 18]. We performed brain and CSF 3-dimensional (3-D) measurements on patients described in our previous report. We hypothesized that 1-D and 3-D brain CT measurements of agerelated brain atrophy would have an association. We also hypothesized that 1-D and 3-D measurements of brain atrophy would be related to post-traumatic $\mathrm{ICH}$.

\section{Methods}

\section{Patient inclusion}

Inclusion criteria were age $\geq 60$ years, fall from standing height or motor vehicle crash, physical evidence of head trauma (i.e., facial fracture, skull fracture, scalp soft tissue injury, facial soft tissue injury, or cervical spine injury), and trauma center admission. Brain CT images were obtained when the patient arrived at the trauma center and stored in the regional picture archiving and communication system (PACS) as digital imaging and communications in medicine (DICOM) files. ICH was determined as absent or present, according to the radiology report, which was confirmed by the first author. For patients with $\mathrm{ICH}$ producing major brain compression (midline shift, lateral ventricular compression, or mesencephalic cistern compression), patients were included, only if they had a CT without brain compression within 6 months prior to their injury.

\section{1-D measurements}

The DICOM files were retrieved from PACS, and the images were opened in a viewer for evaluating brain CT images. Axial views of the brain CT were reviewed to locate and measure the maximal transverse width of the left and right lateral ventricular bodies (i.e., the ventricular width). The brain width (i.e., the right and left transverse distances from the cortical surface to the ipsilateral ventricular margin) was measured at the axial level of the maximal lateral ventricular body width. The intracranial width was computed as the sum of the brain width and the ventricular width. The cortical sulcus width was assessed at the level of the maximal lateral ventricular body width. Cortical atrophy was considered present whenever two or more sulci each had a width $\geq 2.5 \mathrm{~mm}$ with a decreased adjacent gyral width. Central atrophy was considered to be present whenever the lateral ventricular body width was $>30 \mathrm{~mm}$. Composite atrophy was the presence of cortical atrophy, central atrophy, or both. The principal 1-D measurements are depicted in Fig. 1.

\section{3-D measurements}

The DICOM files, produced by a 64 slice GE LightSpeed VCT CT system (Milwaukee, WI), were retrieved from PACS and migrated into the Siemens syngo.via platform (Siemens AG Healthcare Sector, Erlangen, Germany). The DICOM files were then imported into a Siemens Syngo multimodality workplace workstation (VE60A) and converted to a readable format. The CSF volume was computed by including pixels with a Hounsfield range of $0-15$ and the brain volume was calculated from pixels with a Hounsfield range of 22-55. The Hounsfield ranges were selected by the second author, a neuroradiologist, by observing the colored areas of tissues that would be included on the CT images, when various Hounsfield values were used. Intracranial slices included in the 3-D computation were those from the cranial vertex to the foramen magnum (Fig. 2). An example of typical colored areas of included tissue is in Fig. 3 and an infrequent instance with contamination is in Fig. 4. The second author, a neuroradiologist, and the third author, a certified CT technician, supervised the 3-D computation process.

\section{Patient exclusion}

Because patients with $\mathrm{ICH}$ producing major brain compression would not permit accurate 1-D and 3-D measurements, they were excluded, unless a CT scan without brain compression was archived in the PACS within the 6 months prior their injury. Patients were excluded if they met the age and injury criteria, yet the DICOM files would not migrate into the Siemens syngo.via platform.

\section{Ancillary data}

Hospital admission neurologic function was a dichotomization of the Glasgow Coma Scale score. A score of 13-15 represented normal function or minor dysfunction. A score of 3-12 indicated major admission neurologic dysfunction. Hospital death status, age, gender status, and 3-month outcomes were also available. A 3-month outcome was considered to be good, if there was normal or minimally abnormal neurologic function, and bad, if death had occurred or there was severe neurologic dysfunction 


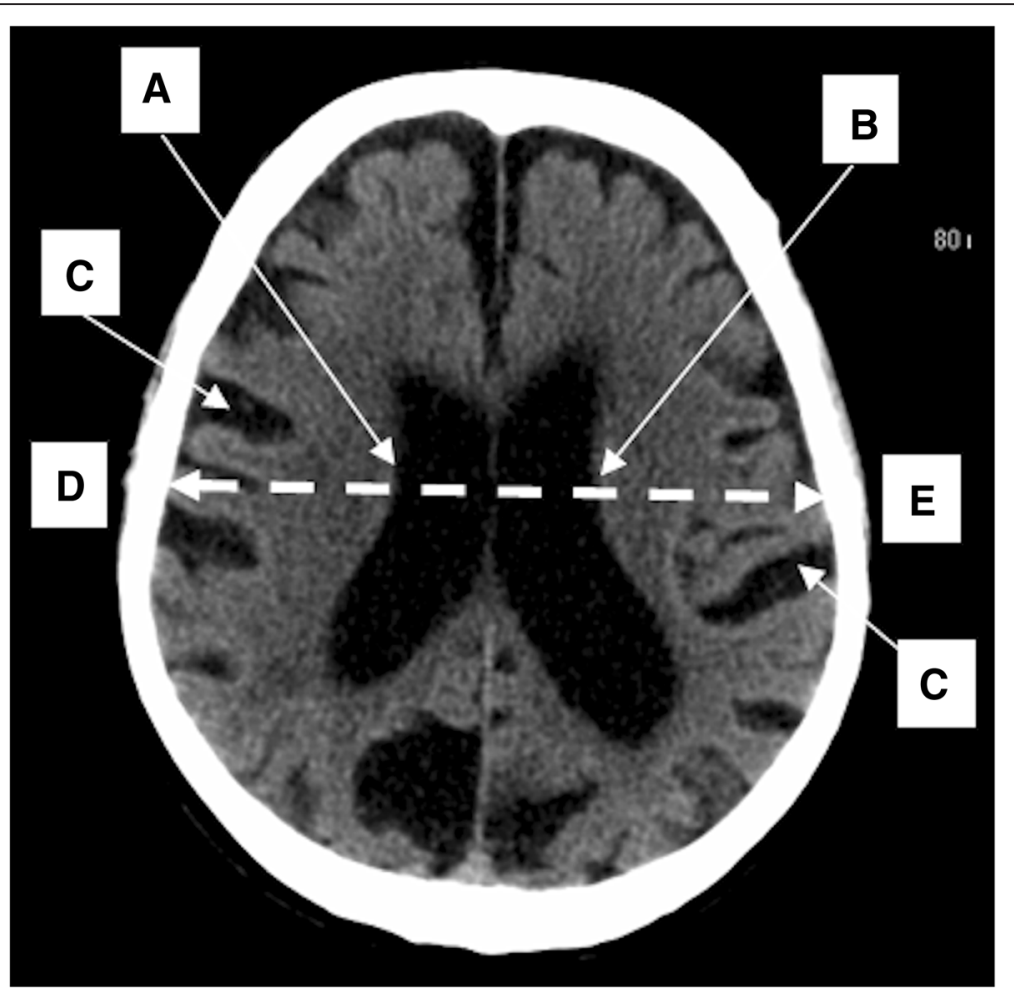

Fig. 1 1-Dimensional Measurements. Transverse distance " $A-$ to- $B$ " is the maximum lateral ventricle body width; " $C$ " is $\geq 2$ cortical sulci, measuring $\geq 2.5 \mathrm{~mm}$ each; and transverse distance " $D-t_{0}-E^{\prime}$ is the intracranial width (at the level of "A-to- $B$ ")

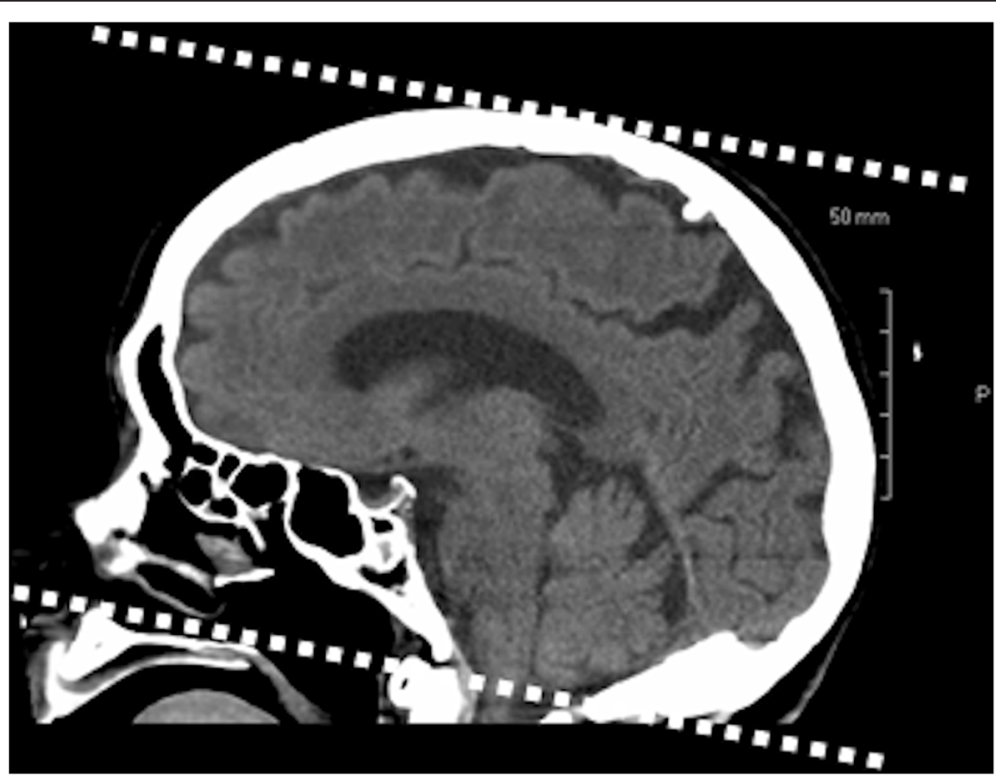

Fig. 2 3-Dimensional Measurements. The 3-dimensional measurements were obtained from the level of the skull vertex and caudal to the level of the foramen magnum 

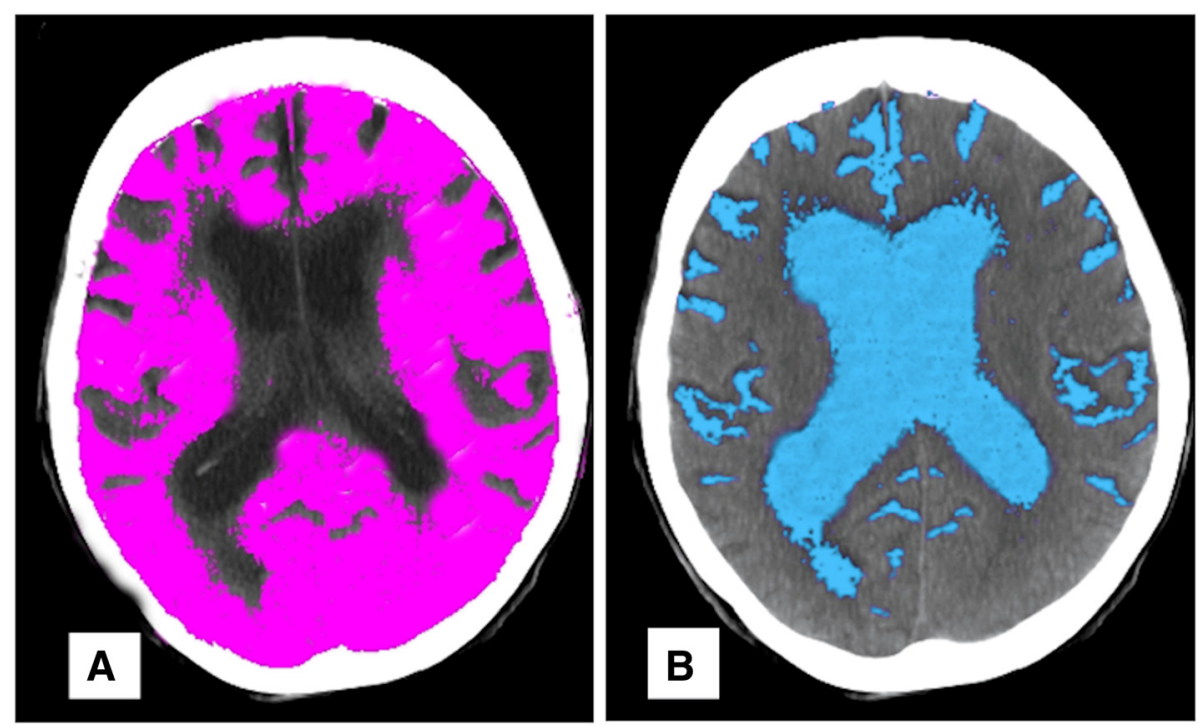

Fig. 3 3-D Threshold Fields. a highlighting of brain parenchyma (Hounsfield range 22-55); b highlighting of CSF (Hounsfield range 0-15)

(vegetative state or coma). Also available in our reliable database was a pre-existing medical condition status for each patient. Conditions included presence or absence of a pre-hospital admission history for dementia, anemia, hypertension, cardiac disease, anti-thrombotic agent use, diabetes mellitus, pulmonary disease, and cerebrovascular accident.

\section{Statistical analysis}

Data were entered into a Microsoft Excel 2010 spreadsheet (Microsoft Corp., Redmond, WA) and imported into SAS System for Windows, release 9.2 (SAS Institute
Inc., Cary, NC), for statistical analyses. For the continuous variable cohort data, standard deviation was used to complement the mean. Pearson correlation analysis was performed for assessing association between two continuous variables. Periodically and for simplification of presentation, cortical sulcus width $\geq 2.5 \mathrm{~mm}$ was expressed as a dichotomous (dummy) variable for correlation analysis. In this circumstance, a one represented its presence and a zero its absence. Wilcoxon Rank Sum test was used to compare continuous data between two groups. Fischer's exact test was used to assess the
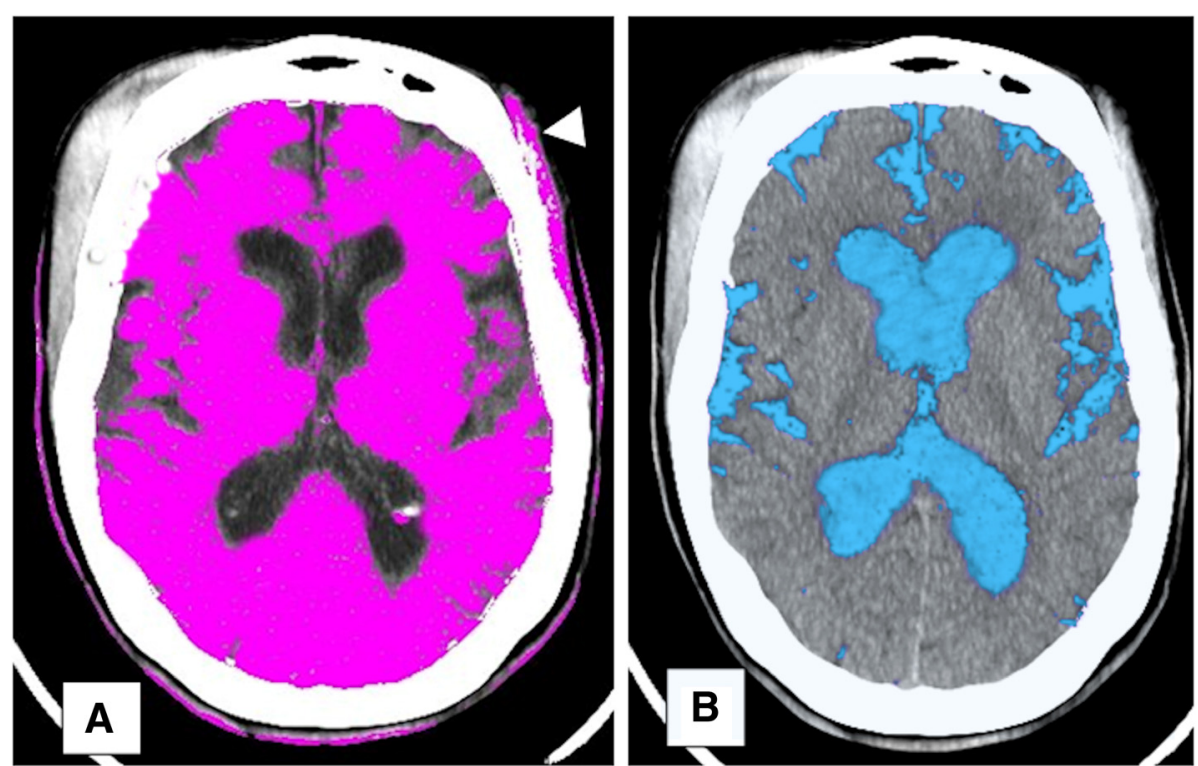

Fig. 4 3-D Threshold Fields. a highlighting of brain parenchyma (Hounsfield range 22-55); b highlighting of CSF (Hounsfield range 0-15). Brain volume contamination in patient with extra-cranial hematoma (a: white arrow) 
relationship of two dichotomous variables. Multivariate logistic regression analysis was performed to assess the relationship between a dependent variable that was dichotomous and potential independent variables. The level of significance was considered $p<0.05$.

\section{Results}

The original cohort included 198 patients with physical evidence of head trauma, age $\geq 60$ years, and an $\mathrm{ICH}$ rate of $36.4 \%(n=72)$. Because ICH created extensive compression and a pre-injury CT within 6 months was unavailable, 1-D estimates of atrophy were not measured in 6 patients. The ICH rate for the 192 patients was $34.9 \%$ $(n=67)$. Of the 192 patients, we did not perform intracranial 3-D estimates of atrophy in 15 (7.8\%), because the DICOM file could not be retrieved from PACS or they failed to migrate into the Siemens workspace. The $\mathrm{ICH}$ rate for these 177 patients was $32.2 \%(n=57)$ and the $\mathrm{ICH}$ rates for these three groups $(36.4 \%, 34.9 \%$, and $32.2 \%)$ were similar $(p=0.7021)$. One hundred seventyseven patients comprise the subset that underwent subsequent analysis. The patients' age was $78.3 \pm 10.0$ years (range, 60-99 years) and the Glasgow Coma Scale score was $14.3 \pm 2.0$ (range, 3-15). Of the 57 patients with ICH included in the analyses, 7 (12.3\%) had major brain compression.

\section{1-D and 3-D associations}

The intracranial 1-D and 3-D outcomes are shown in Table 1.

Age had a negative association with the brain width and brain volume and a positive correlation with a cortical sulcus width $\geq 2.5 \mathrm{~mm}$, the ventricular width $\div$ brain width, ventricular width $\div$ intracranial width, CSF volume, CSF volume $\div$ brain volume, and CSF volume $\div$ intracranial volume; and a trend for a positive association with the ventricular width (Table 2).

Table 1 Intracranial 1-dimensional and 3-dimensional outcome

\begin{tabular}{ll}
\hline & Value \\
\hline 1-Dimensional Measurements: & \\
Ventricular Width (mm) & $31.2 \pm 5.6$ \\
Cortical Sulcus Width $\geq 2.5 \mathrm{~mm}$ & $31.1 \%$ \\
Brain Width (mm) & $90.6 \pm 8.5$ \\
Ventricular Width $\div$ Brain Width (\%) & $34.8 \pm 7.4$ \\
Ventricular Width $\div$ Intracranial Width (\%) & $25.6 \pm 4.0$ \\
3-Dimensional Measurements: & \\
CSF Volume (mL) & $102.5 \pm 63$ \\
Brain Volume (mL) & $1156.4 \pm 198$ \\
Intracranial Volume (mL) & $1258.9 \pm 185$ \\
CSF Volume $\div$ Brain Volume (\%) & $9.5 \pm 6.6$ \\
CSF Volume $\div$ Intracranial Volume (\%) & $8.3 \pm 5.2$ \\
\hline
\end{tabular}

Table 2 Age Correlations

\begin{tabular}{lll}
\hline & r-Value & P-Value \\
\hline 1-Dimensional Measurements: & & \\
Ventricular Width (mm) & +0.13 & 0.0937 \\
Cortical Sulcus Width $\geq 2.5 \mathrm{~mm}$ & +0.35 & $<0.0001$ \\
Brain Width (mm) & -0.28 & 0.0001 \\
Ventricular Width $\div$ Brain Width (\%) & +0.22 & 0.0041 \\
Ventricular Width $\div$ Intracranial Width (\%) & +0.23 & 0.0017 \\
3-Dimensional Measurements: & & \\
Brain Volume (mL) & -0.55 & $<0.0001$ \\
CSF Volume (mL) & +0.28 & 0.0002 \\
CSF Volume $\div$ Brain Volume (\%) & +0.36 & $<0.0001$ \\
CSF Volume $\div$ Intracranial Volume (\%) & +0.38 & $<0.0001$ \\
\hline
\end{tabular}

Pearson correlation analysis was used for statistical assessment; Cortical Sulcus Width $\geq 2.5 \mathrm{~mm}$ was represented as a dichotomous (dummy) variable

Age was $\geq 75$ years in $65.0 \%(115 / 177)$ of the patients and 60-74 years in $35.0 \%(62 / 177)$. The ventricular width was greater for age $\geq 75$ years $(31.9 \pm 5.4 \mathrm{~mm})$, when compared to younger patients $(29.9 \pm 5.8 \mathrm{~mm}$; Wilcoxon Rank Sum test: $p=0.0217)$. The cortical atrophy rate was increased for age $\geq 75$ years $(42.6 \%$ [49/115]), when compared to younger patients $(9.7 \%$ [6/62]; Fischer's exact test: $p<0.0001)$. CSF volume was greater for age $\geq 75$ years $(116 \pm 60 \mathrm{~mL})$, when compared to younger patients $(78 \pm 59 \mathrm{~mL}$; Wilcoxon Rank Sum test: $p<0.0001)$. Brain volume was lower for age $\geq 75$ years $(1086 \pm 164 \mathrm{~mL})$, when compared to younger patients $(1288 \pm 187 \mathrm{~mL}$; Wilcoxon Rank Sum test: $p<0.0001)$.

The ventricular width correlations were negative with the brain volume and positive with the CSF volume, CSF volume $\div$ brain volume, and CSF volume $\div$ intracranial volume (Table 3 ). The cortical sulcus width $\geq 2.5 \mathrm{~mm}$ correlations were negative with the brain volume and positive with the CSF volume, CSF volume $\div$ brain volume, and CSF volume $\div$ intracranial volume (Table 3 ). The brain width correlations were negative with the CSF volume, CSF volume $\div$ brain volume, and CSF volume $\div$ intracranial volume and positive with the brain volume (Table 3 ). The ventricular width $\div$ brain width correlations were negative with the brain volume and positive with the CSF volume, CSF volume $\div$ brain volume, and CSF volume $\div$ intracranial volume (Table 3 ). The ventricular width $\div$ intracranial width correlations were negative with the brain volume and positive with the CSF volume, CSF volume $\div$ brain volume, and CSF volume $\div$ intracranial volume (Table 3 ).

Central atrophy (lateral ventricular body width $>30 \mathrm{~mm}$ ) occurred in $39.5 \%$ and was associated with a reduction in brain volume and an increase in the CSF volume, CSF volume $\div$ brain volume, and CSF volume $\div$ intracranial 
Table 3 1-Dimensional and 3-Dimensional Correlations

\begin{tabular}{lllll}
\hline & CSF volume & Brain volume & CSF volume $\div$ Brain volume & CSF volume $\div$ Intracranial volume \\
\hline Ventricular Width (mm) & $r=0.46$ & $r=-0.13$ & $r=0.42$ & $r=0.43$ \\
& $p<0.0001$ & $p=0.0803$ & $p<0.0001$ & $p<0.0001$ \\
Cortical Sulcus Width $\geq 2.5 \mathrm{~mm}$ & $r=0.45$ & $r=-042$ & $r=0.50$ & $r=0.50$ \\
& $p<0.0001$ & $p<0.0001$ & $p<0.0001$ & $p<0.0001$ \\
Brain Width (mm) & $r=-0.16$ & $r=0.32$ & $r=-0.20$ & $r=-0.21$ \\
Ventricular - Brain Width & $p=0.0392$ & $p<0.0001$ & $p=0.0091$ & $p=0.0057$ \\
& $r=0.45$ & $r=-0.24$ & $r=0.44$ & $r=0.45$ \\
Ventricular - Intracranial Width & $p<0.0001$ & $p=0.0016$ & $p<0.0001$ & $p<0.0001$ \\
& $r=0.46$ & $r=-0.25$ & $r=0.44$ & $r=0.46$ \\
\hline
\end{tabular}

Pearson correlation analysis was used for statistical assessment; Cortical Sulcus Width $\geq 2.5 \mathrm{~mm}$ was represented as a dichotomous (dummy) variable

volume (Table 4). Central atrophy was more frequent with a CSF volume $\geq 100 \mathrm{~mL}$ (57.1\% [44/77]), than with a CSF volume $<100 \mathrm{~mL}(26.0 \%$ [26/100]; Fisher's exact test: $p<0.0001$; odds ratio $[\mathrm{OR}==3.8$ ). Cortical atrophy (cortical sulcus width $\geq 2.5 \mathrm{~mm}$ ) occurred in $31.1 \%$ and was associated with a reduction in the brain volume and an increase in the CSF volume, CSF volume $\div$ brain volume, and CSF volume $\div$ intracranial volume (Table 5). Cortical atrophy was more frequent with a brain volume $<1,100 \mathrm{~mL}$ $(51.3 \%$ [39/76]), than with a brain volume $\geq 1,100 \mathrm{~mL}$ (15.8\% [16/101]; Fisher's exact test: $p<0.0001 ; \mathrm{OR}=5.6)$. Composite atrophy (ventricular or cortical atrophy) occurred in $49.2 \%$ and was associated with a reduction in the brain volume and an increase in the CSF volume, CSF volume $\div$ brain volume, and CSF volume $\div$ intracranial volume (Table 6). Composite atrophy was more frequent with a CSF volume $\div$ brain volume $\geq 9.0 \%$ (68.8 \% [53/ $77])$, than with a CSF volume $\div$ brain volume $<9.0 \%$ (34.0 \% [34/100]; Fisher's exact test: $p<0.0001$; OR $=4.3$ ). Composite atrophy was more frequent with a CSF volume $\div$ intracranial volume $\geq 10.0 \%$ (73.7 \% [42/57]), than with a CSF volume $\div$ intracranial volume $<10.0 \%$ (37.5 \% [45/120]; Fisher's exact test: $p<0.0001 ; \mathrm{OR}=4.7)$.

\section{ICH associations}

$\mathrm{ICH}$ was associated with the ventricular width, ventricular width $\div$ brain width, ventricular width $\div$ intracranial width, central atrophy, cortical atrophy, and composite atrophy (Table 7). ICH was also associated with a decreased brain volume and an increased CSF volume, CSF volume $\div$ brain volume, and CSF volume $\div$ intracranial volume; however, age and gender had no correlation (Table 7). The rate of $\mathrm{ICH}$ progressively increased with central atrophy or cortical atrophy or both (Table 8). Multivariate logistic regression analysis demonstrated that ICH had an independent association with central atrophy $(p=0.0011)$ and cortical atrophy $(p=0.0029)$.

Of the 177 patients, 11 (6.2\%) had major admission neurologic dysfunction and 165 (93.8 \%) did not. The ICH rate was greater in patients with major neurologic dysfunction $(63.6 \%[7 / 11])$, when compared to those without (30.1\% [50/165]; Fischer's exact test: $p=0.0212 ; \mathrm{OR}=4.1)$. The $\mathrm{ICH}$ with compression was also higher for patients with major dysfunction $(27.3 \%$ [3/11]), when compared to those without $(2.4 \%$ [4/165]; Fischer's exact test: $p<0.0001 ; \mathrm{OR}=15.2)$. ICH was more frequent in dying patients $(75.0 \%$ [6/8]), when compared those surviving hospitalization (30.2 \% [51/160]; Fischer's exact test: $p=0.0078)$. ICH with compression was also more frequent in dying patients $(37.5 \%$ [3/8]), when compared those surviving hospitalization (2.4 \% [4/160]; Fischer's exact test: $p<0.0001 ; \mathrm{RR}=1.7)$.

Table 4 Central Atrophy Correlations

\begin{tabular}{|c|c|c|c|}
\hline & No central atrophy & Central atrophy & $P$-Value \\
\hline Number & $107(60.5 \%)$ & $70(39.5 \%)$ & \\
\hline Brain Volume (mL) & $1184 \pm 201$ & $1114 \pm 186$ & 0.0196 \\
\hline CSF Volume $(\mathrm{mL})$ & $81.7 \pm 46.2$ & $134.4 \pm 70.6$ & $<0.0001$ \\
\hline CSF Volume $\div$ Brain Volume (\%) & $7.3 \pm 5.0$ & $12.7 \pm 7.4$ & $<0.0001$ \\
\hline CSF Volume $\div$ Intracranial Volume (\%) & $6.7 \pm 4.0$ & $10.9 \pm 5.7$ & $<0.0001$ \\
\hline
\end{tabular}

Wilcoxon Rank Sum test was used for statistical assessment 
Table 5 Cortical Atrophy Correlations

\begin{tabular}{|c|c|c|c|}
\hline & No cortical atrophy & Cortical atrophy & $P$-Value \\
\hline Number & $122(68.9 \%)$ & 55 (31.1\%) & \\
\hline Brain Volume (mL) & $1211 \pm 188$ & $1034 \pm 162$ & $<0.0001$ \\
\hline CSF Volume (mL) & $83.7 \pm 49.2$ & $144.3 \pm 86.8$ & $<0.0001$ \\
\hline CSF Volume $\div$ Brain Volume (\%) & $7.3 \pm 4.8$ & $14.4 \pm 7.4$ & $<0.0001$ \\
\hline CSF Volume $\div$ Intracranial Volume (\%) & $6.6 \pm 3.9$ & $12.2 \pm 5.5$ & $<0.0001$ \\
\hline
\end{tabular}

\section{Ancillary associations with 1-D and 3-D measurements}

Relative to females, males were found to have increased brain width, increased intracranial width, increased brain volume, increased intracranial volume, and decreased CSF volume $\div$ intracranial volume (Table 9).

Patients with dementia had more cortical atrophy, reduced brain width, increased ventricular $\div$ brain width, increased ventricular $\div$ intracranial width, increased CSF volume, reduced brain volume, increased CSF volume $\div$ brain volume, and increased CSF volume $\div$ intracranial volume (Table 10). Dementia rates were similar for patients with major admission neurologic dysfunction (9.1\% [1/11]) and those without (20.0\% [33/166]; Fischer's exact test: $p=0.0886)$. Females had a higher rate of dementia (27.6\% [24/87]), when compared to males (11.1 \% [10/90]; Fischer's exact test: $p=0.0054)$.

Patients with pre-admission anemia had a higher CSF volume $\div$ brain volume $(n=17 ; 14.4 \%)$, when compared to those without anemia $(n=160 ; 8.9 \%$; Wilcoxon Rank Sum test: $p=0.0010)$. Patients with anemia also had higher ventricular width $\div$ intracranial width $(27.8 \%)$, when compared to no anemia (25.4\%; Wilcoxon Rank Sum test: $p=0.0140)$. Patients with a cardiac history had a higher rate of cortical atrophy (39.7\% [29/73), when compared to no cardiac history (25.0 \% [26/104]; Fisher's exact test: $p=0.0373)$. As well, those with a cardiac history had a greater rate of composite atrophy (60.3\% [44/ $73)$, when compared to patients with no cardiac history (41.4 \% [43/104]; Fisher's exact test: $p=0.0130)$. Patients receiving anti-thrombotic agents also had a higher rate of composite atrophy (54.0\% [61/113]), when compared to those with no use (40.6 \% [26/64]; Fisher's exact test: $p=0.0886$ ). A pre-admission history of diabetes mellitus, pulmonary disease, or cerebrovascular accident did not show any association with the 1-D or 3-D measurements.

Of the 168 patients discharged from the hospital, 137 (81.5\%) had a good outcome at 3-months, and 31 (18.5\%) had a bad outcome. Those with a bad outcome had a higher CSF volume $\div$ brain volume (11.9\%), when compared to patients with a good outcome (9.0\%; Wilcoxon Rank Sum Test: $p=0.0258)$. The major admission neurologic dysfunction rate was greater in patients with a bad outcome (12.9\% [4/31]), when compared to those with a good outcome (1.5\% [2/ 137]; Fischer's exact test: $p=0.0018)$. The rate of prehospital dementia was higher in those with a bad outcome $(35.5 \%[11 / 31])$, when compared to those with a good outcome (16.1 \% [22/137]; Fischer's exact test: $p=0.0140)$. Multivariate logistic regression analysis showed that bad outcome was independently associated with major admission neurologic dysfunction $(p=0.0042)$ and higher CSF volume $\div$ brain volume $(p=0.0125)$. Analysis also demonstrated that bad outcome was independently associated with major admission neurologic dysfunction $(p=0.0072)$ and dementia $(p=0.0123)$.

\section{Discussion}

Relative to our mean population values, other investigators have found comparable results for the ventricular width [19], ventricular width $\div$ intracranial width [3-5, $7]$, CSF volume $[13,18,20]$, brain volume $[13,18,20]$, intracranial volume $[16,18,20,21]$, CSF volume $\div$ brain volume $[13,18]$, and CSF volume $\div$ intracranial volume $[18,21]$. Threshold imperfections were minor and infrequent. The similarity of our values, to those published by other researchers, suggests that our methodological techniques were valid and appropriate.

Table 6 Composite Atrophy Correlations

\begin{tabular}{llr}
\hline & No composite atrophy & Composite atrophy \\
\hline Number & $90(50.8 \%)$ & $87(49.2 \%)$ \\
Brain Volume $(\mathrm{mL})$ & $1208 \pm 194$ & $1103 \pm 188<.0 .0001$ \\
CSF Volume $(\mathrm{mL})$ & $76.8 \pm 42.7$ & $129.1 \pm 68.5$ \\
CSF Volume $\div$ Brain Volume (\%) & $6.7 \pm 4.2$ & $12.3 \pm 7.4$ \\
CSF Volume $\div$ Intracranial Volume $(\%)$ & $6.2 \pm 3.6$ & $<.0001$ \\
\hline
\end{tabular}

Wilcoxon Rank Sum test was used for statistical assessment 
Table 7 Intracranial Hemorrhage Correlations

\begin{tabular}{llll}
\hline & No ICH & ICH & $57(32.2 \%)$ \\
\hline Number & $120(67.8 \%)$ & & \\
1-Dimensional Measurements: & & $33.5 \pm 5.4$ & 0.4 \\
Ventricular Width (mm) & $30.1 \pm 5.3$ & $90.5 \pm 9.1$ & $37.5 \pm 7.6$ \\
Brain Width (mm) & $90.6 \pm 8.3$ & $27.0 \pm 4.0$ & 0.9921 \\
Ventricular Width $\div$ Brain Width (\%) & $33.6 \pm 6.9$ & $37(64.9 \%)$ & 0.0009 \\
Ventricular Width $\div$ Intracranial Width (\%) & $24.9 \pm 3.8$ & $31(54.4 \%)$ & 0.0008 \\
Central Atrophy & $33(27.5 \%)$ & $43(75.4 \%)$ & $<0.0001$ \\
Cortical Atrophy & $24(20.0 \%)$ & & $<0.0001$ \\
Composite Atrophy & $44(36.7 \%)$ & $114.2 \pm 75$ & 0.0001 \\
3-Dimensional Measurements: & & $1089 \pm 172$ & 0.0875 \\
CSF Volume (mL) & $97.0 \pm 55$ & $11.1 \pm 8.0$ & 0.0017 \\
Brain Volume (mL) & $1188 \pm 201$ & $9.6 \pm 6.2$ & 0.0186 \\
CSF Volume $\div$ Brain Volume (\%) & $8.7 \pm 5.6$ & $79.8 \pm 10.0$ & 0.0254 \\
CSF Volume $\div$ Intracranial Volume (\%) & $7.7 \pm 4.5$ & $26(45.6 \%)$ & 0.1861 \\
Age (years) & $77.7 \pm 9.9$ & $61(50.8 \%)$ & 0.5163 \\
Female & &
\end{tabular}

Wilcoxon Rank Sum test was used for statistical analysis of continuous data and Fischer's exact test was used for dichotomous data

\section{Age associations}

We demonstrated multiple correlations of age with the 1-D and 3-D intracranial measurements. We showed that the lateral ventricular body width increased with age, a finding also noted by Meese [19]. Of relevance, age has also been shown to be associated with an increased lateral ventricular volume $[17,22]$, total ventricular volume [14-16], and lateral ventricular volume $\div$ intracranial volume [22]. We found that the ventricular width $\div$ brain width increased with progressive age, a finding also noted by Earnest [3]. Our association of ventricular width $\div$ intracranial width with age has been corroborated by others [5]. Other investigators have also substantiated our finding that the brain volume decreases with advancing age [13, 14, 17, 18]. Similarly, Matsumae [18] and Gur [13] have also noted an increase in the CSF volume with progressive aging. Finally, others have validated our finding that increasing age is associated with an increase in the CSF volume $\div$ intracranial volume $[18,21]$. Our multiple correlations with age, with corroboration by other investigators, imply that our measurements are reliable estimates.

Table 8 Intracranial hemorrhage rates according to the patients' cortical and central atrophy status

\begin{tabular}{llll}
\hline Cortical atrophy & Central atrophy & Patient no. & ICH rate \\
\hline No & No & 90 & $15.6 \%$ \\
Yes & No & 17 & $35.3 \%$ \\
No & Yes & 32 & $37.5 \%$ \\
Yes & Yes & 38 & $65.8 \%$ \\
\hline
\end{tabular}

\section{1-D and 3-D measurement associations}

Multiple associations were noted between the relevant 1-D and 3-D measurements. In particular, logical correlations existed between the brain volume and cortical sulcus width and the brain width. Further, the CSF volume had a statistical and rational correlation with the ventricular width. Finally, the derivative $1-\mathrm{D}$ variables correlated with their logically paired counterpart, e.g., the ventricular width $\div$ intracranial width and CSF volume $\div$ intracranial volume. These logical correlations support the validity of the 1-D and 3-D methods utilized to compute the dimensions. Although we found no publication in the literature that has attempted to correlate 1-D and 3-D measurements, in terms of age-related intracranial structures, the associations were reasonably expected.

We found that central atrophy (i.e., lateral ventricular body width $>30 \mathrm{~mm}$ ) was associated with a reduction in the brain volume and an increase in the CSF volume, CSF volume $\div$ brain volume, and CSF volume $\div$ intracranial volume. Previous investigators have concluded that age-associated brain atrophy is manifested by an increased ventricular size $[5,13-20,22]$, CSF volume [13, $14,18,20]$, and CSF volume $\div$ intracranial volume [18, $21]$ and decreased brain volume $[13,15,17,18,20]$. The present study findings and existing literature indicate that central atrophy is a valid indication of ageassociated brain atrophy.

We found that cortical atrophy (i.e., cortical sulcus width $\geq 2.5 \mathrm{~mm}$ ) was associated with a reduction in the brain volume and an increase in the CSF volume, CSF 
Table 9 Cranial measurements by gender status

\begin{tabular}{llll}
\hline & Male & Female & $P$-value \\
\hline Number & $90(50.8 \%)$ & $87(49.2 \%)$ & \\
1-Dimensional Measurements: & & $30.5 \pm 4.8$ & 0.0923 \\
Ventricular Width (mm) & $31.9 \pm 6.2$ & $33.3 \%$ & 0.5230 \\
Coritcal Sulcus Width $\geq 2.5 \mathrm{~mm}$ & $29.9 \%$ & $87.9 \pm 7.8$ & $<0.0001$ \\
Brain Width (mm) & $93.1 \pm 8.5$ & $118 \pm 9$ & $<0.0001$ \\
Intracranial Width (mm) & $125 \pm 10$ & $35.0 \pm 6.8$ & 0.7551 \\
Ventricular Width $\div$ Brain Width (\%) & $34.6 \pm 8.0$ & $25.7 \pm 3.6$ & 0.6562 \\
Ventricular Width $\div$ Intracranial Width (\%) & $25.5 \pm 4.3$ & $104 \pm 55$ & $1032 \pm 125$ \\
3-Dimensional Measurements: & & $1135 \pm 116$ & 0.8400 \\
CSF volume (mL) & $102 \pm 69$ & $10.4 \pm 6.2$ & $<0.0001$ \\
Brain volume (mL) & $1277 \pm 179$ & $9.2 \pm 4.9$ & 0.0532 \\
Intracranial volume (mL) & $1379 \pm 159$ & 0.0331 \\
CSF Volume $\div$ Brain Volume (\%) & $8.5 \pm 6.8$ & $7.5 \pm 5.3$ & \\
CSF Volume $\div$ Intracranial Volume (\%) & & \\
\hline
\end{tabular}

Wilcoxon Rank Sum test was used for statistical analysis of continuous data and Fischer's exact test was used for dichotomous data

volume $\div$ brain volume, and CSF volume $\div$ intracranial volume. Multiple investigators have provided evidence that the cortical sulcus width increases with age, indicating the presence of brain atrophy [19, 23-25]. Additionally, other researchers have cited evidence that a cortical sulcus width similar to the value used in our study, $\geq 2.5 \mathrm{~mm}$, indicates the presence of cortical atrophy $[6,12$, $19,26]$. The aforementioned indicates that a cortical sulcus width $\geq 2.5 \mathrm{~mm}$ is a manifestation of cortical atrophy.

We established that composite atrophy (ventricular or cortical atrophy) was associated with a reduction in the brain volume and an increase in the CSF volume, CSF volume $\div$ brain volume, and CSF volume $\div$ intracranial volume. Other investigators have also utilized a combination of ventricular and sulcus dimensions as a sign of age-related brain atrophy [5, 27-29].

The multiple associations of the 1-D measurements with the 3-D values imply that both quantitative methods capture similar changes of brain and CSF structures with atrophy. However, the weak correlation coefficients indicate that the two measurements provide distinctive results. That is, 1-D measurements are not a complete quantitative replacement for 3-D interrogation. In particular, lateral ventricular body width principally reflects changes in that specific structure; whereas CSF volumes represent ventricle and extra-ventricle alterations. While 1-D measurements may be more practical, it is likely that $3-\mathrm{D}$ computations might provide more

Table $\mathbf{1 0}$ Cranial measurements by dementia status

\begin{tabular}{llll}
\hline & No dementia & Dementia & $P$-value \\
\hline 1-Dimensional Measurements: & $143(80.8 \%)$ & $34(19.2 \%)$ & \\
Coritcal Sulcus Width $\geq 2.5 \mathrm{~mm}$ & & $47.1 \%$ & 0.0250 \\
Brain Width (mm) & $27.3 \%$ & $86.6 \pm 8.7$ & 0.0022 \\
Ventricular $\div$ Brain Width (\%) & $91.5 \pm 8.2$ & $37.3 \pm 8.3$ & 0.0262 \\
Ventricular $\div$ Intracranial Width (\%) & $34.2 \pm 7.0$ & $27.0 \pm 4.2$ & 0.0288 \\
3-Dimensional Measurements: & $25.3 \pm 3.9$ & & $128.2 \pm 55.2$ \\
CSF Volume (mL) & & $1034 \pm 186$ & 0.0073 \\
Brain Volume (mL) & $96.4 \pm 62.7$ & $1163 \pm 168$ & 0.0001 \\
Intracranial Volume (mL) & $1185.3 \pm 190$ & $13.2 \pm 7.3$ & 0.0007 \\
CSF Volume $\div$ Brain Volume (\%) & $1282 \pm 182$ & $11.3 \pm 5.4$ & 0.0002 \\
CSF Volume $\div$ Intracranial Volume (\%) & $8.6 \pm 6.1$ & $7.6 \pm 4.9$ & 0.001 \\
\hline
\end{tabular}

Wilcoxon Rank Sum test was used for statistical analysis of continuous data and Fischer's exact test was used for dichotomous data 
relevant information, and thus insight, regarding certain aspects of brain atrophy.

\section{ICH associations}

We showed that $\mathrm{ICH}$ was associated with 1-D (i.e., the ventricular width, ventricular width $\div$ brain width, ventricular width $\div$ intracranial width, central atrophy, cortical atrophy, and composite atrophy) and 3-D (i.e., the CSF volume, CSF volume $\div$ brain volume, and CSF volume $\div$ intracranial volume) manifestations of brain atrophy. Although brain atrophy has been promulgated as a risk for ICH [30-34], there was no evidence to support this notion, until our previous publication demonstrated an association with 1-D estimates of brain atrophy [1]. The current study provides additional evidence that $\mathrm{ICH}$ is associated with age-related brain atrophy, represented by intracranial 3-D measurements. To our knowledge, this is the first time that this relationship has been demonstrated.

It is important to note that $\mathrm{ICH}$ had no association with age, although the brain atrophy dimensions correlated with age. Of relevance, the correlation coefficients for age and atrophy manifestations in our study were only moderate to weak. This is exemplified in the study by Gur et al. which showed that advancing age had a negative correlation with the brain volume and a positive association with the CSF volume [13]. However, examination of their scatter plots indicated that there is substantial variance of brain and CSF volumes with each age range. It is likely that this variance is, in part, responsible for the correlation of ICH with brain atrophy, but not with age. That is, the existence of brain atrophy needs to be determined according to the individual's brain imaging and is not an assumption based on age.

$\mathrm{ICH}$ progressively increased with central atrophy, cortical atrophy, and both entities and it had an independent association with central atrophy and cortical atrophy. These findings support the notion that the presence of brain atrophy should be predicated on the basis of both ventricular and cortical sulcus examination. The increased rates of $\mathrm{ICH}$ with major admission neurologic dysfunction and hospital mortality highlight the devastating effects that $\mathrm{ICH}$ can have on clinical outcomes.

\section{Ancillary associations with 1-D and 3-D measurements}

In the current study, males were found to have increased brain width, intracranial width, brain volume, and intracranial volume, and decreased CSF volume $\div$ intracranial volume, when compared to females. Other investigators have also found that males have increased intracranial width [6], brain volume $[13,16,18]$, and intracranial volume [18], relative to females. These observations imply that decreases in female brain volume are likely related to cranial size.

The current investigation demonstrated that dementia patients had more cortical atrophy, reduced brain width, increased ventricular $\div$ brain width, increased ventricular $\div$ intracranial width, increased CSF volume, reduced brain volume, increased CSF volume $\div$ brain volume, and increased CSF volume $\div$ intracranial volume. Of relevance, the literature provides evidence that others have found that dementia is associated with increased cortical sulcal width $[8,35,36]$, increases in lateral ventricular size $[4,35]$, increased lateral ventricular body width-to-intracranial width ratios $[4,8]$, increased ventricle-to-brain area ratio [36], and higher ventricle volume-to-cranial volume quotients [23]. The higher rate of dementia in females, in the current study, may help to explain the lower intracranial volume associated with dementia.

Patients with pre-admission anemia had a proclivity toward brain atrophy, when compared to those without anemia. We are uncertain as to the clinical rationale for this observation. Similarly, patients with history of cardiac disease or those receiving pre-admission antithrombotic agents had an association with increased brain atrophy. The grounds for these findings are also unclear.

The 3-month neurologic dysfunction (bad) outcome was associated with a manifestation of brain atrophy (increased CSF volume $\div$ brain volume), pre-admission dementia, and major admission neurologic dysfunction. These observations seem to be clinically intuitive.

\section{1-D study measurements, a practical method}

Relevant to the primary 1-D brain atrophy measurements used in the current study, a representative summary of the literature is presented in Table 11. The methodological practicality for the current study measurements are considered in context of simplicity or complexity of other methods. Many of the other methods require multiple measurements; mandate that multiple cuts of the brain CT must be analyzed in order to determine the appropriate dimension to be used; or require special software. Relative to outcome associations, an indication of clinical validation, the 1-D measurements used in the current study had multiple significant relationships. Other methods typically had less support. Some of the other methodologies were only validated by a subjective interpretation that atrophy was present $[2,27]$, whereas others provided no evidence of validation in the manuscript $[4,7,11]$. We believe that the principal 1-D measurements used in the current study are practical, objective, and supported by their multiple associations with clinical outcomes and conditions. 
Table 11 Complexity of 1-dimensional atrophy measurements and outcome associations

\begin{tabular}{|c|c|c|c|}
\hline & No. & Methodological complexity: & Outcome associations: \\
\hline \multicolumn{4}{|l|}{ LVB Width: } \\
\hline Current investigation & 177 & S-C & age, ICH, CSF volume \\
\hline Gonzalez, 1978 [2] & 100 & M-C (plus frontal horn width) & atrophy (subjective) \\
\hline \multicolumn{4}{|l|}{ LVB $\div$ IC Width: } \\
\hline Current investigation & 177 & S-C & $\begin{array}{l}\text { age, } \mathrm{CSF} \div \text { brain volume, } \mathrm{CSF} \div \mathrm{IC} \text { volume, } \mathrm{ICH} \text {, } \\
\text { dementia, anemia }\end{array}$ \\
\hline Earnest, 1979 [3] & 59 & S-C & age \\
\hline Gado, 1983 [4] & 24 & $\mathrm{~S}-\mathrm{C}$ & none \\
\hline Steiner, 1985 [5] & 148 & $\mathrm{~S}-\mathrm{C}$ & age \\
\hline \multicolumn{4}{|l|}{ Sulcal Width: } \\
\hline Current investigation & 177 & S-C & $\begin{array}{l}\text { age, CSF volume, brain volume, CSF } \div \text { brain } \\
\text { volume, CSF } \div \text { IC volume, ICH, dementia, cardiac } \\
\text { history }\end{array}$ \\
\hline Ford, 1981 [7] & 59 & M-C (largest sulcus) & none \\
\hline Pirttila, 1992 [9] & 416 & M-C (subjective visual widening) & age, \# medications, DM, HTN, CVA \\
\hline Pasquier, 1996 [10] & 50 & M-C (13 areas; subjective widening) & none \\
\hline Earnest, 1979 [3] & 59 & M-C (sum of 4-largest sulci) & age \\
\hline Gyldensted, 1977 [6] & 100 & M-C (largest width) & age \\
\hline Coyle, 2006 [11] & 35 & S-S (mean width) & none \\
\hline Kochunov, 2008 [12] & 31 & S-S (3-D mean span) & age \\
\hline Gonzalez, 1978 [2] & 100 & M-C (sum 4 largest on highest 3 cuts) & atrophy (subjective) \\
\hline Kohlmeyer, 1983 [8] & 150 & M-C (sum of widest for frontal, temporal, parietal lobes) & age \\
\hline \multicolumn{4}{|l|}{ Composite Atrophy: } \\
\hline Current investigation & 177 & S-C (see LVB Width \& Sulcal Width, above) & $\begin{array}{l}\text { brain volume, CSF volume, CSF } \div \text { brain volume, } \\
\text { CSF } \div \mathrm{IC} \text { volume, ICH, cardiac history, anti-thrombotic } \\
\text { agent use }\end{array}$ \\
\hline Fox, 1975 [27] & 35 & $\begin{array}{l}\text { M-C (sum LVB + frontal horn width; sum } 4 \text { largest sulci, } \\
\text { highest } 2 \text { cuts) }\end{array}$ & atrophy (subjective) \\
\hline Gonzalez, 1978 [2] & 100 & M-C (see above) & atrophy (subjective) \\
\hline
\end{tabular}

LVB lateral ventricular body, S-C single cut, ICH intracranial hemorrhage, CSF cerebrospinal fluid, $M$ - $C$ multiple cuts, IC intracranial, DM diabetes mellitus, HTN hypertension, CVA prior cerebrovascular accident, $S$-S special software

\section{Study limitations}

Although the study was retrospective, the patients included in the study were identified through a reliable process, as described in our previous manuscript [1]. Patients' ICH status was determined by the first-author after reviewing CT scans and reports for the study patients and the credentials of the first author were described in our previous manuscript [1]. Although the current study excluded some patients used in the original study that may have created potential bias, the similarity of the ICH rates mitigates this likelihood. While some may find fault with our 3-D computations using specific CSF and brain parenchymal Hounsfield ranges, similar correlations for the CSF volume $\div$ brain volume and CSF volume $\div$ intracranial volume (CSF volume + brain volume) with other outcomes suggest that the Hounsfield ranges were valid and without CSF volume and brain volume overlap. Hemorrhage may have confounded accurate brain volume computations, in those with $\mathrm{ICH}$. However, the major of patients did not have $\mathrm{ICH}$ and, of those with $\mathrm{ICH}$, the volumes were not extensive.

\section{Conclusions}

The 3-D measurement method seems reasonable based on 1) multiple associations of the values with clinical conditions and outcomes; 2) similarity of results with those in the literature; and 3) examination of the highlighted CT images. The correlation of CT 1-D measurements with 3-D values indicates that the lateral ventricular body width and cortical sulcus width are reliable indicators of age-related brain atrophy. ICH is associated with CT 3-D indicators of brain atrophy, as well as 1-D manifestations. Multiple clinical conditions were also associated with the 1-D measurements. Together, this indicates that our 1-D criteria are valid, relative to clinical 
outcomes and conditions, and 3-D measurements of age-related brain atrophy. Results indicate that the presence of brain atrophy should be based on objective CT 1-D or 3-D measurements, and not only on the patient's age. Because 3-D software is not available on many CT scanners or easy to use, brain atrophy assessment using 1-D measurement is typically more practical and available. Our radiology department is in the process of incorporating lateral ventricular body width $>30 \mathrm{~mm}$ and cortical sulcus width $\geq 2.5 \mathrm{~mm}$ assessment into the radiologist's routine brain CT examination for patients aged $\geq 60$ years. The radiology report will include statements regarding the presence of age-related atrophy changes, when present, and central and cortical atrophy, when criteria are met. We believe that such patient risk stratification will assist in advancing hospital system process improvement and will assist healthcare providers in considering relevant clinical management and prevention strategies.

\section{Ethics approval}

This study was approved by the Mercy Health Youngstown Institutional Review Board for human investigations (\#14-003). The need for written informed consent from the patients was waived, because of the study's retrospective nature. Patient records/information was anonymized and de-identified prior to analysis.

\section{Availability of supporting data}

Due to statutory provisions regarding data- and privacy protection, the dataset supporting the conclusions of this article are only available upon individual request directed to the corresponding author.

\section{Abbreviations}

CSF: Cerebrospinal fluid; CT: Computed tomography; DICOM: Digital imaging and communications in medicine; ICH: Intracranial hemorrhage;

PACS: Picture archiving and communication system.

\section{Competing interests}

The authors declare that they have no competing interests.

\section{Authors' contributions}

All authors conceived the study and participated in the design. CMD, AJC, and AMP organized the image retrieval and image analysis processes. All authors participated in the acquisition of data. CMD and GSH analysed the data. All authors participated in the interpretation of the data. All authors participated in the drafting the article or revising it critically for important intellectual content. All authors read and approved the final manuscript.

\section{Authors' information}

CMD is a retired trauma surgeon, previously board certified in General Surgery and currently certified in Surgical Critical Care; AJC is the Chief of Radiology and is board certified in Neuroradiology; AMP has computed tomography certification by the American Registry of Radiologic Technologists; and GSH is a trauma surgeon and general surgeon and is board certified in General Surgery and Surgical Critical Care.

\section{Acknowledgements}

We thank Marina Hanes for copy editing the previously submitted manuscript and Barbara M. Hileman for assisting the authors with revision of the manuscript.

\section{Author details}

${ }^{1}$ Trauma/Critical Care Services, St. Elizabeth Youngstown Hospital, 1044 Belmont Avenue, Youngstown, OH 44501, USA. ²Division of Radiology, St. Elizabeth Youngstown Hospital, 1044 Belmont Avenue, Youngstown, $\mathrm{OH}$ 44501, USA.

Received: 28 January 2016 Accepted: 21 April 2016

Published online: 26 April 2016

\section{References}

1. Dunham CM, Hoffman DA, Huang GS, Omert LA, Gemmel DJ, Merrell R. Traumatic intracranial hemorrhage correlates with preinjury brain atrophy, but not with antithrombotic agent use: a retrospective study. PLoS One. 2014;9(10):e109473.

2. Gonzalez CF, Lantieri RL, Nathan RJ. The CT scan appearance of the brain in the normal elderly population: a correlative study. Neuroradiology. 1978;16:120-2.

3. Earnest MP, Heaton RK, Wilkinson WE, Manke WF. Cortical atrophy, ventricular enlargement and intellectual impairment in the aged. Neurology. 1979;29(8):1138-43.

4. Gado M, Hughes CP, Danziger W, Chi D. Aging, dementia, and brain atrophy: a longitudinal computed tomographic study. AJNR Am J Neuroradiol. 1983;4(3):699-702.

5. Steiner I, Gomori JM, Melamed E. Progressive brain atrophy during normal aging in man: a quantitative computerized tomography study. Isr J Med Sci. 1985;21(3):279-82.

6. Gyldensted C. Measurements of the normal ventricular system and hemispheric sulci of 100 adults with computed tomography. Neuroradiology. 1977;14(4):183-92.

7. Ford CV, Winter J. Computerized axial tomograms and dementia in elderly patients. J Gerontol. 1981;36(2):164-9.

8. Kohlmeyer K, Shamena AR. CT assessment of CSF spaces in the brain in demented and nondemented patients over 60 years of age. AJNR Am J Neuroradiol. 1983:4(3):706-7.

9. Pirttila T, Jarvenpaa R, Laippala P, Frey H. Brain atrophy on computerized axial tomography scans: interaction of age, diabetes and general morbidity. Gerontology. 1992;38(5):285-91.

10. Pasquier F, Leys D, Weerts JG, Mounier-Vehier F, Barkhof F, Scheltens P. Inter- and intraobserver reproducibility of cerebral atrophy assessment on MRI scans with hemispheric infarcts. Eur Neurol. 1996;36(5):268-72.

11. Coyle TR, Kochunov P, Patel RD, Nery FG, Lancaster JL, Mangin JF, Riviere D, Pillow DR, Davis GJ, Nicoletti MA et al. Cortical sulci and bipolar disorder. Neuroreport. 2006;17(16):1739-42.

12. Kochunov P, Thompson PM, Coyle TR, Lancaster JL, Kochunov V, Royall D, Mangin JF, Riviere D, Fox PT. Relationship among neuroimaging indices of cerebral health during normal aging. Hum Brain Mapp. 2008;29(1):36-45.

13. Gur RC, Mozley PD, Resnick SM, Gottlieb GL, Kohn M, Zimmerman R, Herman G, Atlas S, Grossman R, Berretta D et al. Gender differences in age effect on brain atrophy measured by magnetic resonance imaging. Proc Natl Acad Sci U S A. 1991;88(7):2845-9.

14. Pfefferbaum A, Mathalon DH, Sullivan EV, Rawles JM, Zipursky RB, Lim KO. A quantitative magnetic resonance imaging study of changes in brain morphology from infancy to late adulthood. Arch Neurol. 1994;51(9):874-87.

15. Resnick SM, Pham DL, Kraut MA, Zonderman AB, Davatzikos C. Longitudinal magnetic resonance imaging studies of older adults: a shrinking brain. J Neurosci. 2003;23(8):3295-301.

16. Akdogan I, Kiroglu Y, Onur S, Karabuluti N. The volume fraction of brain ventricles to total brain volume: a computed tomography stereological study. Folia Morphol. 2010;69(4):193-200.

17. Fjell AM, McEvoy L, Holland D, Dale AM, Walhovd KB. Brain changes in older adults at very low risk for Alzheimer's disease. J Neurosci. 2013;33(19):8237-42.

18. Matsumae M, Kikinis R, Morocz IA, Lorenzo AV, Sandor T, Albert MS, Black PM, Jolesz FA. Age-related changes in intracranial compartment volumes in normal adults assessed by magnetic resonance imaging. J Neurosurg. 1996;84(6):982-91. 
19. Meese W, Kluge W, Grumme T, Hopfenmuller W. CT evaluation of the CSF spaces of healthy persons. Neuroradiology. 1980;19(3):131-6.

20. Blatter DD, Bigler ED, Gale SD, Johnson SC, Anderson CV, Burnett BM, Parker N, Kurth S, Horn SD. Quantitative volumetric analysis of brain MR: normative database spanning 5 decades of life. AJNR Am J Neuroradiol. 1995;16(2):241-51.

21. Takeda S, Matsuzawa T. Measurement of brain atrophy of aging using X-ray computed tomography: sex difference in 1045 normal cases. Tohoku J Exp Med. 1984;144(4):351-9.

22. Barron SA, Jacobs L, Kinkel WR. Changes in size of normal lateral ventricles during aging determined by computerized tomography. Neurology. 1976;26(11):1011-3.

23. Turkheimer E, Cullum CM, Hubler DW, Paver SW, Yeo RA, Bigler ED. Quantifying cortical atrophy. J Neurol Neurosurg Psychiatry. 1984:47(12):1314-8.

24. Kochunov P, Mangin JF, Coyle T, Lancaster J, Thompson P, Riviere D, Cointepas Y, Regis J, Schlosser A, Royall DR et al. Age-related morphology trends of cortical sulci. Hum Brain Mapp. 2005;26(3):210-20.

25. Drayer BP. Imaging of the aging brain. Part I. Normal findings. Radiology. 1988;166(3):785-96.

26. Ishii T. A comparison of cerebral atrophy in CT scan findings among alcoholic groups. Acta Psychiatr Scand Suppl. 1983;309:1-30.

27. Fox JH, Topel JL, Huckman MS. Use of computerized tomography in senile dementia. J Neurol Neurosurg Psychiatry. 1975;38(10):948-53.

28. Gado M, Patel J, Hughes CP, Danziger W, Berg L. Brain atrophy in dementia judged by CT scan ranking. AJNR Am J Neuroradiol. 1983;4(3):499-500

29. Wu S, Schenkenberg T, Wing SD, Osborn AG. Cognitive correlates of diffuse cerebral atrophy determined by computed tomography. Neurology. 1981;31(9):1180-4

30. Holmes JF, Hendey GW, Oman JA, Norton VC, Lazarenko G, Ross SE, Hoffman JR, Mower WR. Epidemiology of blunt head injury victims undergoing ED cranial computed tomographic scanning. Am J Emerg Med. 2006;24(2):167-73.

31. Ellis GL. Subdural hematoma in the elderly. Emerg Med Clin North Am. 1990:8(2):281-94.

32. Hanif S, Abodunde O, Ali Z, Pidgeon C. Age related outcome in acute subdural haematoma following traumatic head injury. Ir Med J. 2009;102(8):255-7.

33. Gangavati AS, Kiely DK, Kulchycki LK, Wolfe RE, Mottley JL, Kelly SP, Nathanson LA, Abrams AP, Lipsitz LA. Prevalence and characteristics of traumatic intracranial hemorrhage in elderly fallers presenting to the emergency department without focal findings. J Am Geriatr Soc. 2009;57(8):1470-4.

34. Doherty DL. Posttraumatic cerebral atrophy as a risk factor for delayed acute subdural hemorrhage. Arch Phys Med Rehabil. 1988;69(7):542-4.

35. Bird JM. Computerized tomography, atrophy and dementia: a review. Prog Neurobiol. 1982;19(1-2):91-115.

36. Wurthmann C, Bogerts B, Falkai P. Brain morphology assessed by computed tomography in patients with geriatric depression, patients with degenerative dementia, and normal control subjects. Psychiatry Res. 1995;61(2):103-11.

\section{Submit your next manuscript to BioMed Central and we will help you at every step:}

- We accept pre-submission inquiries

- Our selector tool helps you to find the most relevant journal

- We provide round the clock customer support

- Convenient online submission

- Thorough peer review

- Inclusion in PubMed and all major indexing services

- Maximum visibility for your research

Submit your manuscript at www.biomedcentral.com/submit
Biomed Central 